\title{
Comparison between the in situ and laboratory water retention curves for a silty sand
}

\author{
A. Askarinejad, F. Casini, P. Kienzler \& S.M. Springman \\ Institute for Geotechnical Engineering, ETH Zürich, Switzerland
}

\begin{abstract}
After an extreme rainfall event in May 2002 a series of landslides occurred in Ruedlingen in Canton Schaffhausen, North Switzerland. A $38^{\circ}$ steep slope has been chosen in this area beside the river Rhine to carry out an artificial rainfall experiment to investigate the dependence between rainfall, suction, saturation and shear resistance. Two sprinkling experiments were conducted to represent an extreme rainfall event, the second of which resulted in failure of $130 \mathrm{~m}^{3}$ of the slope. Several cycles of wetting and drying were applied to the soil and suction and volumetric water content were measured at different depths in three locations of the slope, by which in-situ Water Retention Curves (WRC) can be derived. The WRC of an undisturbed sample was also determined from laboratory test. The in situ and laboratory WRCs are compared in this paper and the differences will be discussed.
\end{abstract}

\section{INTRODUCTION}

The stability of slopes depends directly on the distribution of pore pressures inside its mass. This distribution can be strongly influenced by rainfall due to the infiltration of water into the slopes (Alonso et al. 1995). The description, quantification and study of soil water flow processes leads to a consideration of the hydraulic properties of unsaturated soils. This involves the relationship between the soil water content, the hydraulic conductivity, and the soil water retention function, which relates the soil water content to the capillary suction (Braddock et al. 2001).

Soil water retention can be determined both in the laboratory and in the field. In the former, both values of suction and water content are measured in the same sample, while in the field the measurements are done at two different points and over different soil volumes.

The differences between insitu and laboratory WRCs have been investigated and attributed to inadequate representation of large pores in laboratory, scale effects in the sample, disturbance, the spatial variability of the soil, hysteresis and overburden pressure (Field et al. 1985; Shuh et al. 1988).

Several cycles of wetting and drying were applied to the soil, suction and volumetric water content were measured at different depths in three locations of the slope, by which in-situ Water Retention Curves (WRC) of the soil were derived. The WRC of undisturbed sample was also determined from laboratory tests and will be compared with the insitu results in this paper.

\section{TEST FIELD}

The selected experimental area is a steep, forested slope in Ruedlingen, North Switzerland, where 42 surficial landslides occurred (Fischer et al. 2003) in spring 2002, after an extreme rainfall $(100 \mathrm{~mm}$ fell in 40 minutes).

To investigate the hydrological and mechanical behaviour of the slope, a sprinkling experiment was carried out in autumn 2008. This test was followed by a triggering experiment in spring 2009 . This paper is based on the data from the first test.

\subsection{Geometry}

The selected experimental area is located on an east facing slope on the banks of the river Rhine (Springman et al. 2009). The altitude is about 350 masl. The average gradient of the slope was determined using a total station theodolite to be $38^{\circ}$. During the preliminary investigations, sandstone and marlstone were located at a depth of between $0.5 \mathrm{~m}$ to more than $5 \mathrm{~m}$ along the $30 \mathrm{~m} \times 7.5 \mathrm{~m}$ plan section.

\subsection{Infiltration characteristics}

Infiltration characteristics were evaluated with combined sprinkling and dye tracer tests. The tests were replicated across three different locations near to the investigated area (TP 3, TP 4, TP 5; Figure 1). The experiments revealed high infiltration capacity of the soil. No overland flow was observed during the sprinkling at any of the three locations. After 


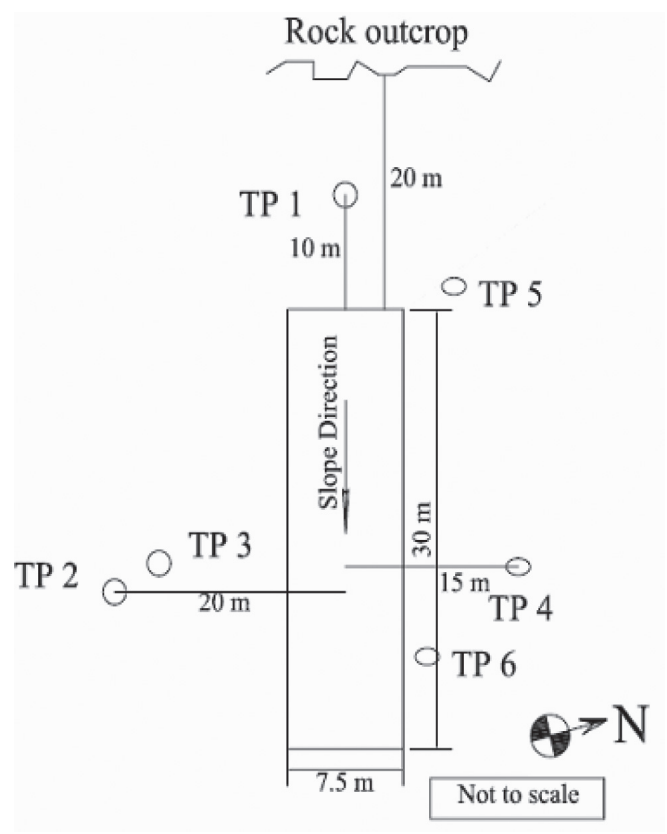

Figure 1. Test site plan showing dimensions and position of Test Pits (TP).

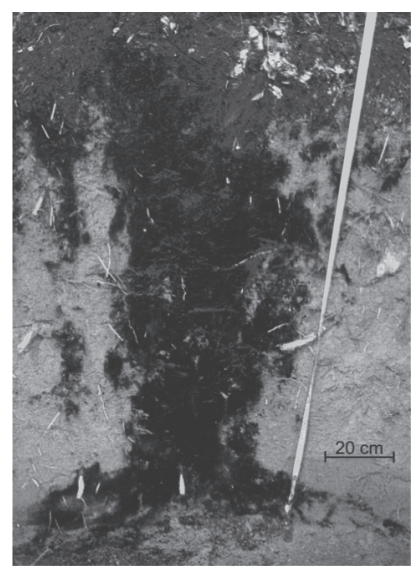

Figure 2. Dye pattern in the middle section of TP5.

excavation, flow paths of the infiltrated water were clearly visible by the dye patterns (Figure 2). In summary, the dye patterns showed complete and homogeneous saturation of the whole soil profile with only little preferential drainage and with perched saturation above the bedrock. With regard to the planned landslide triggering experiment, these results confirmed the high vulnerability of the slope to failure and led to expectations of a more deep-seated failure above the transition to bedrock rather than a more surficial failure that is typical for many rainfall-induced landslides (Springman et al. 2003).

However, stained fractures below the subsoil revealed that substantial drainage might occur into the bedrock, which may prevent complete saturation and failure of the instrumented slope (Springman et al. 2009).

\subsection{Laboratory classification}

The behaviour of soil was investigated under saturated and unsaturated conditions (Springman et al. 2009, Casini et al. 2010a \& b). The average saturated permeability of soil was determined to be $\mathrm{k}_{\mathrm{sat}}=1 * 10^{-7} \mathrm{~m} / \mathrm{s}$.

The grain-size distributions at different depths of TP2 are shown in Figure 3. The silt and clay fractions increase with depth, while the sand fraction decreases. The soil can be classified as MediumLow plasticity silty sand (ML) according to USCS.

The soil Water Retention Curve (WRC), which links suction $s=u_{a}-u_{w}$ and volumetric water content $\theta_{w}=V_{w} / V$ for a natural sample is presented in Figure 4. The WRC was obtained under suction

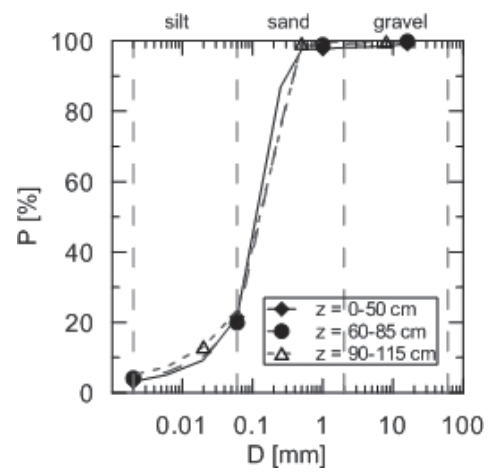

Figure 3. The grain size distribution at different depths of TP2.

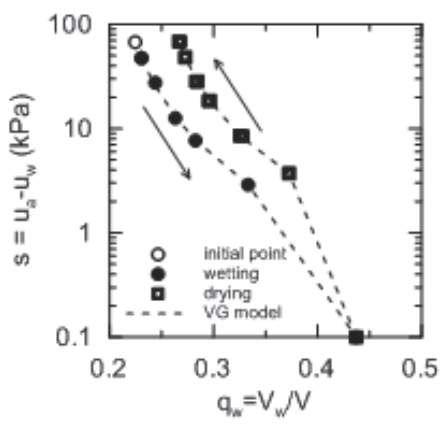

Figure 4. Water retention curve of an undisturbed sample $\mathrm{z}=120 \mathrm{~cm}(\mathrm{TP} 2)$. 
controlled conditions with a Fredlund Apparatus (Perez Garcia et al. 2008). As the first step, a suction of $\mathrm{s}=70 \mathrm{kPa}$ was imposed to the sample and some water was expressed from the soil. Therefore, the suction in the natural sample was less than $70 \mathrm{kPa}$. In the continuation step, the sample absorbed some water, following a scanning curve until reaching the main wetting and the main drying during desaturation (Figure 4).

The experimental points were fitted with the Van Genuchten (VG) model (1980):

$\frac{\theta_{w}-\theta_{\text {wres }}}{\theta_{\text {wsat }}-\theta_{\text {wres }}}=\left[\frac{1}{1+(\alpha s)^{n}}\right]^{m}$

where $\alpha, n, m$ are parameters while $\alpha>0, m>0$, $n>1$ and $m=1-1 / n . \theta_{\text {wsat }}$ and $\theta_{\text {wres }}$ are the saturated and residual volumetric water content, respectively. The values for the wetting and drying branch are reported in Table 1.

The air entry value is $\mathrm{s}_{\mathrm{aev}}=2.7 \mathrm{kPa}$ for the drying curve, which is consistent with the WRC expected for sandy soils (Lu and Likos, 2004).

\subsection{Instrumentation}

An extensive instrumentation plan was designed to measure hydrological and geo-mechanical responses of the slope. Detailed measurements of soil suction, water level and soil volumetric water content were measured combined with an investigation of subsurface flow at the lowest part of the slope by means of tracer experiments. Deformations were monitored during the experiment, both on the surface via photogrammetrical methods and within the soil mass, using a flexible probe equipped with strain gauges at different points and two axis inclinometers on the top (Askarinejad 2009).

The instruments were installed mainly in three clusters over the slope. The instruments included jet-fill tensiometers, TDRs, Decagons, piezometers, soil temperature sensor, deformation probes, earth pressure cells, acoustic sensors and rain gauges (Figure 5). The tensiometers were installed at depths of $15,30,60,90,120$, and $150 \mathrm{~cm}$ below the ground surface in each cluster. Decagons were installed at shallow depths of

Table 1. van Genuchten parameters for Ruedlingen silty sand.

\begin{tabular}{lllll}
\hline & $\theta_{\text {wsat }}[-]$ & $\theta_{\text {wres }}[-]$ & $\alpha[\mathrm{kPa}-1]$ & $\mathrm{N}[-]$ \\
\hline Wetting & 0.44 & 0.20 & 0.90 & 1.53 \\
Drying & 0.44 & 0.25 & 0.37 & 1.72 \\
\hline
\end{tabular}

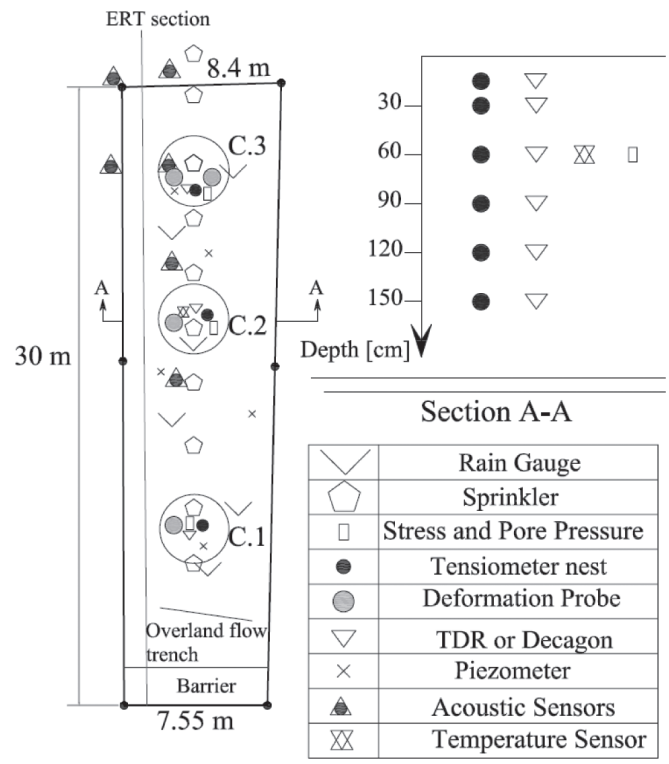

Figure 5. Instrumentation plan and section.

15 to $60 \mathrm{~cm}$ every $15 \mathrm{~cm}$, and TDRs from $60 \mathrm{~cm}$ to $150 \mathrm{~cm}$, with aspacing of $30 \mathrm{~cm}$. All the instruments were calibrated and checked in the laboratory for proper functioning before installation in the field.

The hydrological responses of the soil were measured during the experiment with logging interval of 5 minutes.

\section{EXPERIMENTAL PROCEDURE AND INSITU MEASUREMENTS}

\subsection{Applied rainfall}

The artificial rainfall was applied by means of 10 sprinklers with the same spacing located on the middle longitudinal line of the field. The lower sprinklers experienced higher hydraulic heads as the water was supplied from the upper part of the slope. Therefore, the rainfall was not uniformly distributed. The average applied rain intensity is shown in Figure 6 a.

As indicated in this figure the rain was applied with an average intensity of $35 \mathrm{~mm} / \mathrm{hr}$ for 3 hours as the first wetting phase (W1), followed by a 20 hour stop allowing the soil to drain (first drying phase-D1). Afterwards, the slope was sprinkled for 1.5 days with an average intensity of $17 \mathrm{~mm} / \mathrm{hr}$, which increased with a first shock of $45 \mathrm{~mm} / \mathrm{hr}$ to average value of $30 \mathrm{~mm} / \mathrm{hr}$ for another 1.5 days (second wetting phase-W2) and then the second drying phase started (D2). 


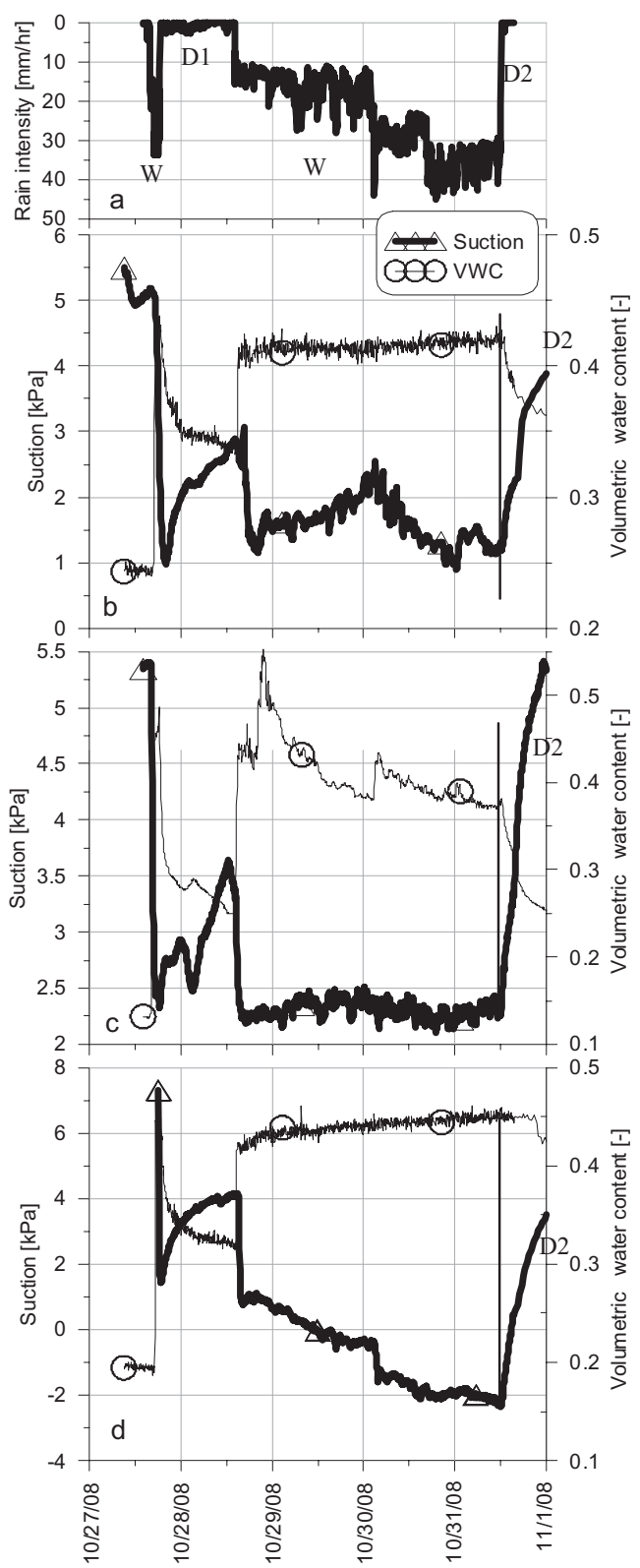

Figure 6. (a) Average applied rain intensity, (b) Variations of volumetric water content and matric suction in cluster 1 at depth of $60 \mathrm{~cm}$, (c) cluster 2 at depth of $30 \mathrm{~cm}$, and (d) cluster 2 at depth of $120 \mathrm{~cm}$.

\subsection{Insitu water retention curves}

Figures $6 \mathrm{~b}, \mathrm{c}$, and d show the variations of Volumetric Water Content (VWC) and matric suction at three different depths of 30,60 , and $120 \mathrm{~cm}$ in clusters 1 and 2.

After changes in the intensity of applied rainfall, the suction and volumetric water content measurements respond without significant time discrepancy in all 3 depths. This verifies the high infiltration capacity of the soil obtained from the earlier hydrological investigations.

At some points during the second wetting phase of the rainfall, the changes in VWC and suction are not contemporaneous. This can be due to either the hysteretic effect of the soil-water retention curve or the difference in the location of the sensors at each depth.

In figures $6 \mathrm{~b}$ and $\mathrm{c}$, at the beginning of the second drying phase (D2), the VWC drops as the suction increases, but in cluster 2 at depth of $120 \mathrm{~cm}$ (Figure $6 \mathrm{~d}$ ), the suction increases up to $2.5 \mathrm{kPa}$ and only after this point the VWC starts to decrease. This point can be described as the air entry value of the WRC which is consistent with the value derived from the laboratory test $\left(\mathrm{s}_{\text {aev }}=2.7 \mathrm{kPa}\right)$.

Figures 7 to 9 show the insitu WRC derived from Figures 6 b, c, \& d respectively, compared with laboratory curve.

The first wetting branch (W1) shows higher values of suction at the same VWC compared with first drying curve (D1), which is in contrast with the

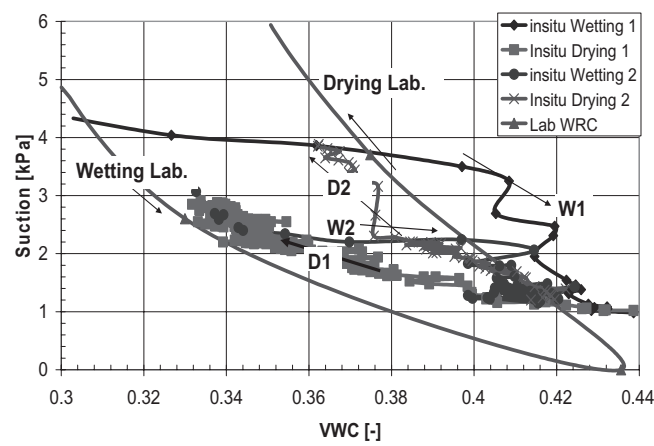

Figure 7. Insitu water retention curve of cluster 1 at depth of $60 \mathrm{~cm}$ compared with laboratory results.

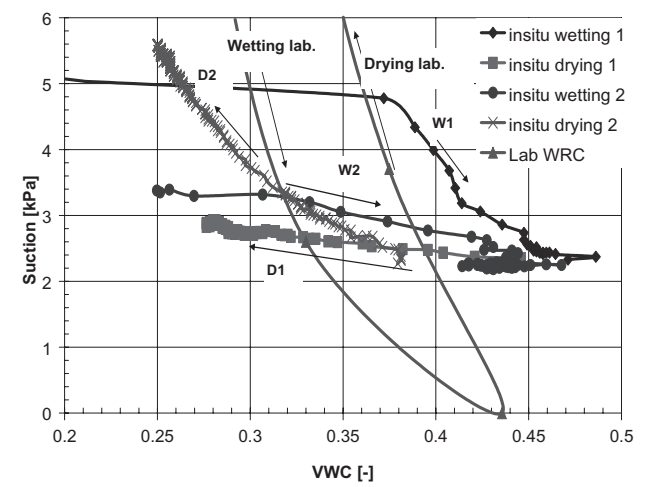

Figure 8. Insitu water retention curve of cluster 2 at depth of $30 \mathrm{~cm}$ compared with laboratory results. 


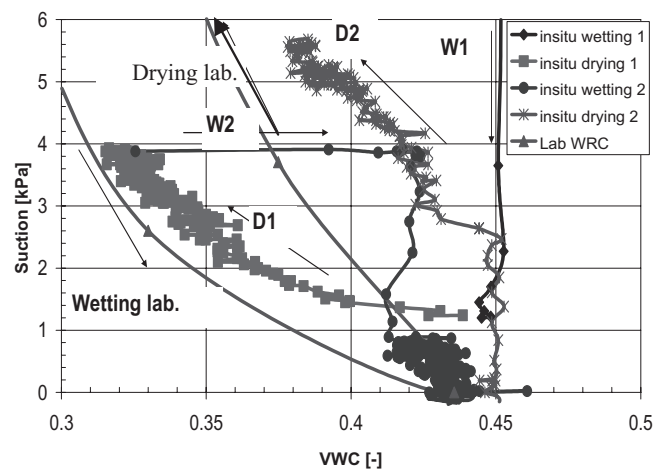

Figure 9. Insitu water retention curve of cluster 2 at depth of $120 \mathrm{~cm}$ compared with laboratory results.

unsaturated-soils hysteresis theory (Mualem 1973). There are two hypotheses for this observation.

i. As the soil is loose and the overburden pressures are low, therefore, the volume of the soil could increase during the wetting due to reduction in effective stress (swelling), and on the other hand during the drying period, the soil volume decreases because of the build up of suction and increase in effective stresses.

ii. As the soil is granular and its response to the applied rainfall is relatively fast (medium to high permeability), small heterogeneity in the flow paths from the surface to the tensiometers and TDRs, like small channels due to dead roots, can affect the response time. Therefore, especially during the intense wetting phases, the readings of sensors at each time are maybe not exposed to the same conditions.

Also, it should be noted that tensiometers measure suction in a thin soil layer around a ceramic cup of $7 \mathrm{~cm}$ length and a diameter of $2.2 \mathrm{~cm}$, whereas a TDR measures soil volumetric water content in a cylindrical soil volume with a diameter and length of $5 \mathrm{~cm}$ and $15 \mathrm{~cm}$, respectively.

There is also a possibility that the branches of W1, D1, and W2 in the insitu WRCs are not the main drying curves but are scanning curves. Accordingly, in order to be sure that the changes in suction and volumetric water content are on a main branch of the curve, the last drying part of the curves (D2) of clusters 1 and 2 at different depths has been compared with the drying branch of the curve obtained from the laboratory test. The results are presented in Figures $10 \& 11$.

In Figure 10, the laboratory curve is in quite good agreement with the insitu measurements. In cluster 1 , the curves related to the depths of $120 \mathrm{~cm}$ and $90 \mathrm{~cm}$ show air entry values of around $2.2 \mathrm{kPa}$. This value is lower than the one implied by the laboratory WRC, which can be related to

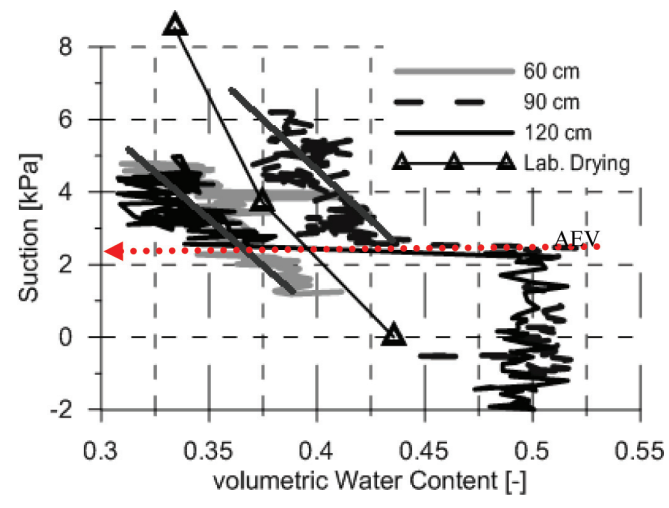

Figure 10. Drying curve of insitu WRC for cluster 1 compared with laboratory results.

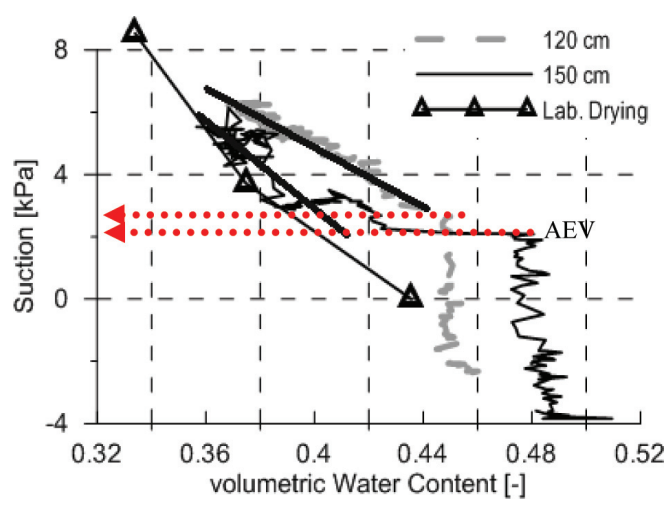

Figure 11. Drying branch of insitu WRC for cluster 2 compared with laboratory results.

the void ratio difference between the soil at these depths and the void ratio of the natural sample tested in the laboratory $(\mathrm{e}=0.8)$.

The insitu void ratio of the soil can be calculated from the volumetric water content under saturated conditions and using Equations 1 and 2.

$$
\begin{aligned}
& \theta=S_{r} \cdot n, \\
& S_{r}=1 \Rightarrow \theta_{s}=1 \times n_{s} \\
& e=\frac{n}{1-n}
\end{aligned}
$$

The void ratios calculated from this approach are 1.04 and 0.96 at depths of $90 \mathrm{~cm}$ and $120 \mathrm{~cm}$, respectively.

Similarly, in cluster 2 (Figure 11) at a depth of $120 \mathrm{~cm}$, the air entry value is marginally higher than the one at $150 \mathrm{~cm}$, while the soil has a lower void ratio at $120 \mathrm{~cm}$ compared with the one at $150 \mathrm{~cm}$.

The data from figures 10 and 11 suggest that the trend lines of the insitu drying branches are less steep than the line from the laboratory results. 
This observation can be attributed to the fact that the laboratory curve has been derived from a one dimensional drainage path, while the insitu condition is a three-dimensional situation and the water can flow in different directions rather than only vertically, also it can be due to the different porosity of insitu and laboratory test. Therefore, the differential water capacity defined as $d \theta / d s$ is higher from field data than from laboratory data in the range of low soil water matric potentials. This should result in slower infiltration predictions based on the sorptivity from the laboratory data. These and similar observations indicate the need to pay more attention to the effects of scale on soil hydraulic properties (Pachepsky et al. 2001).

\section{FURTHER TEST PLANS}

In order to investigate the effect of cycles of wetting and drying on the void ratio of the soil, a series of tests will be performed on undisturbed samples from different depths of the slope profile, loaded to the same overburden pressures as in the field.

Also, more laboratory WRC tests will be done on undisturbed samples from different depths with higher resolution at higher VWCs and suctions lower than $15 \mathrm{kPa}$.

\section{CONCLUSION}

Two cycles of wetting and drying has been applied on a natural, steep, forested slope in northern Switzerland. At 3 different points of the slope, and at 6 depths, the values of volumetric water content and suction have been measured. Partial agreement was observed comparing the insitu values with a laboratory derived WRC on an undisturbed sample. In some of the insitu WRCs, it was observed that at the same water content, the wetting branch shows higher values of suction than the drying branch. This can be due to the change in void ratio of the soil during wetting and drying, to the heterogeneity of the soil along the flow path from the surface to the measurement depth of different sensors, and the difference in response time of different types of devices. The hypothesis of volume change and effect of initial porosity of the soil on the WRC will be investigated by testing samples with different void ratios.

The trend lines of the drying branches of insitu WRCs are less steep than the line from laboratory results. This observation is attributed to the fact that the laboratory curve has been derived from a one dimensional drainage path, while three-dimensional flow is possible under situation insitu condition or also this can be related to the effect of sampling and needs to be verified by further laboratory tests.

\section{ACNOWLEDGEMENTS}

This research was funded by the Competence Centre for Environment and Sustainability (CCES) within the framework of the TRAMM-Project. Marco Sperl and Ernst Bleiker helped with the fieldwork. We are grateful to the Gemeinde of Ruedlingen and their President Mrs. Katy Leutenegger for giving permission to carry out this experiment on their land.

\section{REFERENCES}

Alonso, E. Gens, A. \& Lloret, A. 1995. Effect of rain infiltration on the stability of slopes. In Proc. of the 1st Intern. Conf. on Unsaturated Soils, Paris: 241-249. Rotterdam: Balkema.

Askarinejad A. 2009. A method to locate the slip surface and measuring subsurface deformations in slopes. 4th Intern. Young Geotechnical Engineers' Conf., Alexandria, Egypt: 171-174.

Braddock, R.D. Parlange, J.-Y. \& Lee, J. 2001. Application of a soil water hysteresis model to simple water retention curves. Transport in Porous Media, 44: 407-420.

Casini, F. Jommi, C. Springman, S.M. 2010a. A laboratory investigation on an undisturbed silty sand from a slope prone to landsliding. Granular Matter 12 (DOI: 10.1007/s10035-010-0182-y).

Casini, F., Minder, P., Springman, S.M., 2010b. Shear Strength of an unsaturated silty sand (this issue).

Field, J.A. Parker, J.C. \& Powell, N.L. 1985. Comparison of field- and laboratory measured and predicted hydraulic properties of soil with macropores. Soil Sci. 138: 385-396.

Fischer, C. López, J. Springman, S.M. 2003. Remediation of an eroded steep slope in weathered sandstone after a major rainstorm. Intern. Conf. on Landslides, Hong Kong: 878-883.

Lu, N. Likos, W. 2004. Unsaturated soil mechanics, Wiley, New Jersey.

Mualem, Y. 1973. Modified approach to capillary hysteresis based on a similarity hypothesis, Water Resour. Res., 9: 1324-1331.

Pachepsky, Y. Rawls, W.J. \& Giménez, D. 2001. Comparison of soil water retention at field and laboratory scales. Soil Sci. Soc. Am. J. 65: 460-462.

Perez-Garcia, N. Houston, S.L. Houston, W.N. Padilla, J.M. 2008. An oedometer-type Pressure Plate SWCC Apparatus. Geotechnical Testing Journal 31: 1-9.

Springman, S.M. Jommi, C. Teysseire P. 2003. Instabilities on moraine slopes induced by loss of suction: a case history. Géotechnique, 53 (1): 3-10.

Springman, S.M. Kienzler, P. Casini, F. Asakrinejad, A. 2009. Landslide triggering experiment in a steep forested slope in Switzerland. 17th Intern. Conf. of Soil Mech. \& Geot. Eng. Alexandria, Egypt: 1698-1701.

Shuh, W.M. Cline, R.D. \& Sweeney, M.D. 1988. Comparison of a laboratory procedure and a textural model for predicting in situ water retention. Soil Sci. Soc. Am. J. 52:1218-1227. 